\title{
Study on Science and Technology Innovation Ability of Research and Development Institutions in Jilin Province-Taking Natural Sciences as an Example
}

\author{
Zhang Nini ${ }^{2}$, Wang Guihua ${ }^{1}$, Li Henan ${ }^{1}$, Zhang $\mathrm{Ke}^{1}$, Liu Jingyan ${ }^{1}$, Chang Haiyan ${ }^{3}$, Liu Xiaoxi ${ }^{1}$, Guo Mohan ${ }^{1}$, Jing \\ Liwei $^{1 *}$ \\ Jilin Province Science and Technology Information Institute, Changchun , Jilin 130033 \\ Changchun China Optical Science \&Technology Museum, Changchun, Jilin130117 \\ Changchun Guanghua University, Changchun , Jilin 130000
}

\begin{abstract}
Research and development institutions are the main components of the development of science and technology. The relevant statistics of $R \& D$ institutions is an important basis for providing decision-making reference for leaders at all levels, and its construction and development are essential to improving provinces' independent innovation ability. Taking the research and development institutions of natural sciences as examples, this paper makes a detailed analysis from the aspect of development situation, innovation ability construction and the problems existing in the construction process, and puts forward some suggestions and incentive policies for the combination of enterprise, university and institute.
\end{abstract}

Keywords-Research and development institutions; Natural science; Innovation ability; Suggestion

\section{DEVELOPMENT STATUS OF SCIENTIFIC RESEARCH INSTITUTIONS IN THE NATURAL SCIENCE FIELD OF JILIN PROVINCE}

In recent years, the development of the research and development institutions in the field of natural science in Jilin province is closely integrated with the reform of scientific and technological system, and has achieved good results. In 2013, it was launched that is about the Notice of Jilin Provincial Committee and Jilin Provincial Government on Deepening the Reform of Scientific and Technological System and Accelerating Implementation of Opinions and Division of Tasks on Scientific and Technological Innovation (hereinafter referred to as the "Notice"). In the "Notice", the requirements for the reform of scientific research institutes and the schedule of progress were carefully deployed: the public welfare scientific research institutes adhere to the direction of social public welfare service and optimize the service consciousness; the research and development institutions are developing in the direction of the enterprise, relying on the market as the guidance, integrating the innovative resource advantages of the existing research and development institutions, making a good service for enterprises, forming a number of technical transfer demonstration institutions, and improving the scientific and technological innovation ability of the research and development institutions in our province [1]. By 2016, Jilin province has established 82 research and development institutions at or above the county level and subordinated to the government departments in the field of natural sciences and technology in strategic emerging industries, agriculture, etc. Among them, 6 research and development institutions are subordinated to the central government. Since the "13th FiveYear Plan", the research and development institutions in the field of natural sciences and technology have maintained a steady development trend. In 2016, there were 11043 practitioners and the total income of the expenditure amounted to RMB 5,130,000,000, which was the same as that of 2015; the total expenditure amounted to RMB 4,970,000,000, including the science and technology expenditure of RMB $3,630,000,000$, an increase of $6.15 \%$ and $2.97 \%$ respectively from 2015.

\section{CONNOTATION OF THE RESEARCH AND DEVELOPMENT INSTITUTIONS IN THE FIELD OF NATURAL SCIENCE AND \\ EVALUATION SYSTEM OF SCIENTIFIC AND TECHNOLOGICAL INNOVATION ABILITY}

\section{A. Connotation of the research and development institutions in the field of natural science}

The research and development institutions in the field of natural science mainly engage in scientific and technological activities in relevant fields of scientific research and technology development. Compared with the social, cultural and scientific information fields, a great deal of financial resources, material resources, human resources and information resources are required and the output results are diverse. In the new period of accelerating regional innovation ability, how to seek progress in stability, continuously develop advantages, and develop innovation are the new requirements faced by research and development institutions in the field of natural science. 


\section{B. Evaluation system of scientific and technological} innovation ability for institutions in the field of natural science

Combining with the nature and characteristics of the institutions in the field of natural science in Jilin province, this paper sets up the evaluation system of scientific and technological innovation ability in the field of natural science, which mainly focuses on the structural elements of science and technology innovation ability, such as the fundamental innovation strength, innovation input ability, project implementation ability, achievement output ability and transformation diffusion ability. The research sets up 21 evaluation systems of secondary indicators. Among them, the fundamental innovation strength and innovation input ability is the macroscopic trends of the dynamic monitoring of science and technology innovation capability of scientific research institutions. The purpose of core competence assessment such as project implementation ability, achievement output ability and transformation diffusion ability is to evaluate the important work and level of scientific research institutions. [2] Besides, the CRITIC method is used to empower the innovation ability index system of the institutions in the field of natural science. The specific index system is shown in Table 1:

TABLE I. THE INNOVATION ABILITY INDEX SYSTEM OF THE INSTITUTIONS IN THE FIELD OF NATURAL SCIENCE IN JILIN PROVINCE

\begin{tabular}{|c|c|c|c|c|}
\hline & Primary index & Weighting & Secondary index & Weighting \\
\hline \multirow{20}{*}{$\begin{array}{l}\text { Innovation ability of } \\
\text { scientific research } \\
\text { institutes }\end{array}$} & & & The number of scientific and technological activists (X11) & 0.150 \\
\hline & Fundamental & & $\begin{array}{c}\text { The proportion of the scientific and technological activists with } \\
\text { the master degree or above (X12) }\end{array}$ & 0.166 \\
\hline & $\begin{array}{l}\text { innovation strength } \\
\text { X1 }\end{array}$ & 0.295 & $\begin{array}{c}\text { The income from overhead in scientific and technological } \\
\text { activities (X13) }\end{array}$ & 0.311 \\
\hline & & & $\begin{array}{c}\text { The original value of scientific research instruments and } \\
\text { equipment (X14) }\end{array}$ & 0.373 \\
\hline & & & $\begin{array}{l}\text { Per-capita overhead input in science and technology activities } \\
\text { for the scientific and technological activists (X21) }\end{array}$ & 0.273 \\
\hline & Innovation input & 080 & $\begin{array}{c}\text { The proportion of the R\&D personnel with the master degree } \\
\text { or above (X22) }\end{array}$ & 0.322 \\
\hline & ability X2 & 0.089 & $\begin{array}{c}\text { The proportion of the R\&D personnel to the scientific and } \\
\text { technological activists (X23) }\end{array}$ & 0.200 \\
\hline & & & $\begin{array}{l}\text { The proportion of the overhead input in } \mathrm{R} \& \mathrm{D} \text { to the overhead } \\
\text { input in science and technology activities (X24) }\end{array}$ & 0.205 \\
\hline & & & $\begin{array}{c}\text { The number of the R \& D subjects per-capita for the scientific } \\
\text { and technological activists (X31) }\end{array}$ & 0.084 \\
\hline & & & $\begin{array}{l}\text { The proportion of the number of subjects in application } \\
\text { research and test development to the total number of subjects }\end{array}$ & 0.084 \\
\hline & $\begin{array}{l}\text { Project } \\
\text { implementation } \\
\text { ability X3 }\end{array}$ & 0.237 & $\begin{array}{l}\text { The proportion of the science and technology projects } \\
\text { entrusted by enterprises to the total number of R\&D subjects } \\
\text { (X33) }\end{array}$ & 0.369 \\
\hline & & & $\begin{array}{l}\text { Conditions of R \& D subjects coming from the government } \\
\text { (X34) }\end{array}$ & 0.215 \\
\hline & & & $\begin{array}{l}\text { Construction conditions of science and technology R \& D } \\
\text { platform (X35) }\end{array}$ & 0.248 \\
\hline & & & $\begin{array}{l}\text { The weighted number of per-capita patent application and } \\
\text { acceptance for the scientific and technological activists (X41) }\end{array}$ & 0.220 \\
\hline & Achievement output & 0107 & $\begin{array}{l}\text { The total number of effective invention patents per-capita for } \\
\text { the scientific and technological activists (X42) }\end{array}$ & 0.327 \\
\hline & ability X4 & 0.191 & $\begin{array}{c}\text { The number of per-capita patent authorization for the scientific } \\
\text { and technological activists (X43) }\end{array}$ & 0.293 \\
\hline & & & $\begin{array}{c}\text { The number of papers published on CNKI per-capita for the } \\
\text { scientific and technological activists (X44) }\end{array}$ & 0.160 \\
\hline & $\begin{array}{l}\text { Transformation } \\
\text { diffusion ability } \times 5\end{array}$ & 0.181 & $\begin{array}{l}\text { The proportion of the non-government source technical income } \\
\text { to the income from science and technology activities (X51) } \\
\text { The proportion of the number of full-time staff in the } \\
\text { transformation and diffusion of achievements to the scientific } \\
\text { and technological activists (X52) }\end{array}$ & 0.323 \\
\hline & & & Total information amount of social network so far (X53) & 0.088 \\
\hline & & & $\begin{array}{l}\text { Construction conditions of the transfer and transformation } \\
\text { platform for the scientific and technological achievements } \\
\text { (X54) }\end{array}$ & 0.390 \\
\hline
\end{tabular}


Taking the data of the institutions in the field of natural science in Jilin Province in 2015 as examples, this paper made the systematic analysis and calculation on 84 institutions in the field of natural science that have filled the data according to the value-determined standard of the innovation ability index system of the institutions in the field of natural science in Table 1 , and in accordance with the results of the survey of the annual science and technology institution in 2015. The conclusions are as follows:

Among the 84 institutions in the field of natural science in Jilin Province, 5 of them were subordinated to the central government. The comprehensive innovation ability of Changchun Institute of Optics, Fine Mechanics and Physics, Chinese Academy of Sciences, Changchun Institute of Applied Chemistry Chinese Academy of Sciences, and Northeast Institute of Geography and Agroecology, Chinese Academy of Sciences rank the Top three. Among them, compared with the project implementation ability of the provincial scientific research institutions, the science and technology activity of the central institutions is the most active. The first is the large investment in science and technology. In 2015, the expenditure amount on science and technology of the research and development institutions subordinated to the central government departments that all belong to the scientific research institutions in the field of natural science was RMB $2,191,000,000$, an increase of $6.76 \%$ over the previous year, accounting for $59.04 \%$ of the total expenditure on science and technology of all research and development institutions; the R\&D internal expenditure amounted to RMB 2,174,000,000, accounting for $75.65 \%$ of the total R\&D internal expenditure of all research and development institutions. The second is the high level of the scientific and technological activists. There were 3,334 people engaged in scientific and technological activities in the research and development institutions subordinated to the central government departments, accounting for $97.23 \%$ of the practitioners, among whom 1222 were doctors, accounting for $35.14 \%$ of the practitioners, and 1,429 had senior professional titles, accounting for $41.09 \%$ of the practitioners. In addition, among the R\&D personnel, $70.04 \%$ of the people were engaged in the scientific research. The third is the strong application and transformation ability of the scientific and technological achievements. In the R\&D internal expenditures of the research and development institutions subordinated to the central government departments, the applied research was RMB 1,027,000,000, accounting for 47.22\%; the experimental development was RMB 958,000,000, accounting for $44.06 \%$; the basic research was RMB $189,000,000$, accounting for $8.71 \%$. Fourthly, the output ability of scientific and technological achievements was strong. There were 2466 scientific papers published, of which 1320 were published abroad, accounting for $53.53 \%$. There were 8 scientific publications and 698 invention patents, of which 495 were authorized patents.

III. The Problems In the DeVElopment Process OF THE RESEARCH AND DEVELOPMENT INSTITUTIONS IN THE NATURAL FIELD

Our province has achieved remarkable achievements in promoting the innovation ability of scientific research institutions and changing the way of economic development, but there are still some factors that restrict the development of the research and development institutions in the natural field of our province in terms of resource allocation, talent reserve, technology investment and mechanism.

\section{A. The science and technology activities of the research and development institutions in the natural field are heavily dependent on the government funds.}

For the long time, the scientific and technological inputs are directly proportional to the scientific and technological outputs. The greater the inputs, the more considerable the outputs. However, the insufficiency of the research and development institution's own science and technology input is the main problem that restricts its development. The reasons for this problem are: Compared with the developed provinces, most of the research and development institutions in the natural fields in our province belong to the establishment of public service units, which cannot create more economic benefits by themselves. Secondly, most of the scientific and technological input of scientific research institutions comes from the government funds. The subject expenditures and $R \& D$ expenditures of the research and development institutions subordinated to the central government departments account for the largest proportion of the total amount of scientific research institutions, but most of the expenditures they obtained came from government support. For example, the subject expenditures of the central government departments and local government departments are RMB 989,000,000 and RMB135,000,000 respectively, while the expenditures from the enterprise are only RMB 21,506,000, and the government expenditures input accounts for $98.10 \%$ of the total expenditures; regarding the R\&D internal expenditures of the research and development institutions subordinated to central government departments, the amount of funds from the government is RMB 2,099,000,000, accounting for $96.53 \%$ of the R\&D internal expenditures. 


\section{B. Research and development institutions in the natural field need to break barriers in systems and mechanisms}

Different types of research and development institutions in the natural field have different systems and mechanisms. The systems and mechanisms are constantly changing and developed and they are difficult to maintain synchronization, which will restrict the progress of research and development institutions. Therefore, the effective connection of the systems and mechanisms is the difficult problem that the research and development institutions need to crack, which is specifically manifested as follows: Firstly, it is the system and mechanism matching and connection between the institutional attributes and the main business. At present, from the operation of the institutional system, some of the institutions are engaged in public welfare activities, and some of the institutions mainly carry out product development and industrialization. Therefore, there are different management systems and mechanisms in the institutions, which will thence result in some contradictions and problems. It is very important to develop a mutually integrated management operation mechanism and system for the future development of institutions. Secondly, it is the restructuring of the research and development institutions and the selection of main business development direction. Institutional restructuring involves many problems such as personnel placement, business development orientation and so on, and all aspects need to be allocated and arranged properly. [3]

\section{The problem of insufficient reserve of talents}

Talent is an inexhaustible motive force for scientific and technological innovation and it is the main force that leads the regional innovation development in our province. However, there is a serious lack of excellent talents in the research and development institutions of our province. Firstly, compared with other developed provinces, our province has a certain gap in terms of talent treatment, work and living environment, which leads to the relatively obvious high-level talent outflow phenomenon between the research and development institutions. Secondly, in the process of reform for some public welfare institutions, because the supporting policies are not comprehensive enough, it will cause to provide less welfare for scientific and technical personnel. Compared with the staff at the same level in colleges or universities, some local research and development institutions have less welfare, thereby reducing the work enthusiasm of the scientific and technical personnel and leading to the constant shrinking of the scale of scientific and technological personnel, the large outflow of talents as well as the difficult introduction of high-level talents. At the same time, there are too many researchers in the institutions and the proportion of industrialization and market development talents is low, which reduces the institutional transformation and industrialization level of the institutions. To build a new era of innovative scientific research institutions, it needs to reserve good talents and make good use of talents.

\section{The achievement transformation and industrialization level of the research and development institutions needs to be improved.}

Firstly, the scientific and technological output of scientific research institutions is mainly based on the basic research results such as the papers, and there are few application results that can be converted into products. The results that have obtained the scientific and technical awards above the provincial level are less. Secondly, there is the lack of application technology reserves. There are fewer patents, trademarks and copyrights with independent intellectual property rights. Thirdly, the combination of enterprise, university and institute is not close enough. In recent years, the research and development institutions have mainly cooperated with universities and have less cooperation with enterprises. In addition, the scientific research institutions in our province haven't established too many platforms for the research and development and promotion of the scientific and technological achievements. For example, the number of key laboratories undertaken by them above the provincial level is less. They don't have high enthusiasm in participating in the engineering and technology R\&D centers. Therefore, there is a need to improve the ability of scientific research institutions to undertake major tasks and promote the transformation of results. [4]

\section{COUNTERMEASURES AND SUGGESTIONS ON THE DEVELOPMENT OF NATURAL SCIENTIFIC RESEARCH INSTITUTIONS}

To better make the advantages and lead role scientific research institutions in the natural field of our province and improve the level of regional innovation ability in our province, the following countermeasures are proposed.

\section{A. Encourage the cooperation between the scientific research institutions and enterprises}

Most of the funds in the construction process of the natural scientific research institutions in our province come from the government funds, while those coming from the supporting funds of the enterprises are relatively less. The enterprise is the main battlefield for the achievement transformation and industrialization, which is the closest link to the market. Therefore, to encourage the scientific research institutions to broaden their sources of funds by strengthening cooperation with enterprises is beneficial for the transformation and industrialization of the research results of scientific research institutions as soon as possible. 


\section{B. Launch the incentive distribution mechanism to stimulate} the enthusiasm of the scientific and technical personnel

Continue to implement the employment system combining the permanent staff and the temporary employees in the scientific research institutions, improve the assessment system, set up the appraisal index system according to the main business of the institutions, and give the specific weight. The appraisal system is aiming at all staff in the post. According to the scores of each individual and the results of the democratic evaluation, comprehensive rankings are given, differential wages are given, and staffs with contributions are highly-paid and employed. Study the establishment of a high-level talent support system, encourage and allow the scientific research institutions to hire high-level talents, top-notch talents and raise the social security level of high-level talents. High-level talents who partially or urgently need to be introduced are given wellpaid in accordance with the relevant regulations of the state and the province. Combine the various provisions on the transfer of the Scientific and Technological Achievements in Implementation Plan of Promoting Transfer and Transformation of Scientific and Technological Achievements in Jilin Province and Regulations on Promoting Transformation of Scientific and Technological Achievements in Jilin Province to encourage the scientific and technological personnel to carry out innovation and transformation of scientific and technological achievements [5].

\section{Improve various supporting policies}

It is recommended that the scientific research institutions should be exempted from import duties and import-link valueadded tax and consumption tax in scientific and technological development products imported by the scientific research institutions within a reasonable amount. For the scientific research institutions with overall or partial corporate restructuring, they are exempted from enterprise income tax, the urban land use tax and real estate tax of self-use land for scientific research and development and the residential property. Scientific research institutions serve the technical training, technical consultation, technical services, technological results transfer and technology contracting in all walks of life. The technical service income is exempt from corporate tax [6].

\section{CONCLUSION}

At the present, Jilin Province is in the critical period of implementing innovation-driven development. As the main body of science and technology output - a scientific research institution in the field of natural science, its construction and development is very necessary and significant to perfect the regional innovation system and complement the short board of original innovation and insufficient supply of core technologies

\section{ACKNOWLEDGMENT}

Fund Project: This paper belongs to the National Science and Technology Statistic Project STS-2016-15, "Study on the Evaluation and Analysis of the Innovation Ability of Scientific Research Institutes — Taking Jilin Province as an Example".

Profile of the Author: Zhang Nini (1987- ), female, born in Changchun, Jilin Province, Changchun China Optical Science \&Technology Museum. Jing Liwei (1982- ), female, born in Harbin, Heilongjiang Province, Associate Researcher of Jilin Province Science and Technology Information Institute.

\section{REFERENCES}

[1] On the Printing, Issuance and Implementation of the Notice of the CPC Jilin Provincial Committee and the People's Government of Jilin Province on Deepening the Reform of Scientific and Technological System and Accelerating the Implementation of Opinions and Division of Tasks on Scientific and Technological Innovation by the General Office of the People's Government of Jilin Province. JZBF [2013] No. 4.

[2] He Yingbo et al. Research on evaluation of science and technology innovation ability of Stated-owned Military Institute. Science Research Management, 2016, V37 (3): 68-72.

[3] Zhang Hongli et al. Research on the innovation ability construction of main scientific research institutions in Guangdong Province under the new situation. Science \& Technology and Economy, Issue 3, 2017.

[4] Jilin province exhausts its efforts to support the scientific and technological innovation of small and medium-sized enterprises. China Industry News. 2013.

[5] Notice of the General Office of the State Council on Printing and Issuance of the Action Plan for Promoting the Transfer and Transformation of Scientific and Technological Achievements (GBF [2016] No. 28) and Opinions of the CPC Jilin Provincial Committee and the People's Government of Jilin Province on the Further Implementation of the Innovation-Driven Development Strategy and Promoting the Comprehensive Rejuvenation of the Old Industrial Base (JF [2016] No. 26).

[6] Li Hai. To play the role of policies and regulations to promote the development of scientific research institutions with restructuring. Economic and Social Development. 2009, 7(6). 